\title{
ASPECTOS ECOFISIOLÓGICOS E CRESCIMENTO EM PLANTAS DE MILHO SUBMETIDAS AO ALAGAMENTO
}

\author{
Carla Carolynne Resueno Coelho' ${ }^{1}$;aomara Nascimento da Silva ${ }^{2}$; Myriam Galvão \\ Neves $^{2}$; Antonia Gilcileia Cunha da Conceição ${ }^{3}$; Raimundo Thiago Lima da Silva ${ }^{4}$; \\ Cândido Ferreira de Oliveira Neto ${ }^{5}$.
}

\footnotetext{
${ }^{1}$ Universidade Federal Rural da Amazônia. Capitão Poço, Pará, Brasil. carol.resueno@ gmail.com ${ }^{2}$ Universidade Federal Rural da Amazônia. Capitão Poço, Pará, Brasil. ns_jaomara@ hotmail.com

${ }^{3}$ Universidade Federal Rural da Amazônia. Capitão Poço, Pará, Brasil. gilcileia.cunha@gmail.com

${ }^{4}$ Universidade Federal Rural da Amazônia. Capitão Poço, Pará, Brasil. thiagoufra@ hotmail.com

${ }^{5}$ Universidade Federal Rural da Amazônia. Capitão Poço, Pará, Brasil. candido.neto@ufra.edu.br
}

\begin{abstract}
RESUMO: Todos os aspectos de crescimento e desenvolvimento das plantas podem ser afetados pela deficiência hídrica e saturação de água nos tecidos, causada pela excessiva demanda evaporativa e/ou limitado suprimento de água. As conseqüências na planta pelo alagamento vão ser clorose, murchamento prematuro, queda da capacidade fotossintética, do potencial hídrico e da concentração de nutrientes nas folhas e diminuição no crescimento. $\mathrm{O}$ objetivo desse trabalho foi avaliar os efeitos do alagamento sob conteúdo relativo de água, transpiração, condutância estomática, relação raiz/ parte aérea e massa seca total em plantas de milho submetidas ao alagamento. O experimento foi conduzido em casa de vegetação da Universidade Federal Rural da Amazônia (UFRA - Capitão - Poço), utilizando-se plantas de milho variedade BR 5102, o delineamento experimental foi inteiramente casualizado (DIC) com fatorial $2 \times 4$, com duas condições hídricas: controle, déficit hídrico e quatro ciclos de estresse com cinco repetições. Obtiveram-se resultados significativos em todos os parâmetros avaliados, concluindo que o alagamento influenciou negativamente na ecofisiologia da planta e na massa seca total.
\end{abstract}

PALAVRAS-CHAVE: anoxia, conteúdo relativo de água, transpiração.

\section{ECOPHYSIOLOGICAL ASPECTS AND GROWTH IN CORN SUBJECT TO FLOODING}

\begin{abstract}
All aspects of growth and development of plants can be affected by water stress and water saturation in the tissues caused by excessive evaporative demand and / or limited water supply. The consequences of flooding at the plant will be chlorosis, wilting premature decline in photosynthetic capacity, water potential and the concentration of nutrients in leaves and decreased growth. The aim of this study was to evaluate the effects of flooding on relative water content, transpiration, stomatal conductance, the root / shoot and total dry matter in maize plants subjected to flooding. The experiment was conducted in a greenhouse at the Federal Rural University of Amazonia (UFRA - Capitão Poço), using corn plant variety BR 5102, the experimental design was completely randomized design (CRD) with $2 \times 4$ factorial, with two conditions water: control, drought and four cycles of stress with 15 repetitions. Achieved significant results in all parameters evaluated, concluding that the flooding negatively in the ecophysiology of plant and total dry mass.
\end{abstract}

KEYWORDS: anoxia, relative water content, transpiration. 
A busca de genótipo de plantas que sejam tolerantes ao excesso de água no solo tem apresentado importância crescente, pois o alagamento e o encharcamento do solo são episódios recorrentes em muitas áreas do planeta.

Além disso, as perspectivas de maior incidência de eventos climáticos extremos, como chuvas excessivas, em decorrência das mudanças climáticas globais (SUMARY et al., 2007). As consequências na planta pelo alagamento vão ser clorose, murchamento prematuro, queda da capacidade fotossintética, do potencial hídrico e da concentração de nutrientes nas folhas e diminuição no crescimento.

O objetivo desse trabalho foi avaliar os efeitos do alagamento sob conteúdo relativo de água, transpiração, condutância estomática, relação raiz/ parte aérea da massa seca e massa seca total em plantas de milho sob alagamento.

$\mathrm{O}$ experimento foi conduzido em casa de vegetação da Universidade Federal Rural da Amazônia, Unidade Descentralizada de Capitão Poço, coordenadas geográficas $01^{\circ} 44^{\prime} 04^{\prime}$ 'S e $47^{\circ} 03^{\prime} 28^{\prime \prime} \mathrm{W}$, com altitude média de $96 \mathrm{~m}$.

Os vasos foram preenchidos com terra preta (Latossolo amarelo, textura média) e esterco de galinha, na proporção de 3:1, respectivamente, e semeadas com a variedade de milho BR 5102, no qual cada unidade experimental foi composta de uma planta vasos.

O delineamento experimental utilizado foi o inteiramente casualizado, com cinco repetições, e duas condições hídricas, assim especificadas: controle e solo alagado. A aplicação do alagamento foi realizada a partir do $25^{\circ}$ dias após a germinação, durante 10 dias.

Foram feitas coletas destrutivas das plantas no estágio vegetativo (35 dias) para determinar a biometria das plantas.

A área foliar das plantas foi medida através do medidor de área foliar do modelo AM 300 e a biomassa após secagem a $65^{\circ} \mathrm{C}$ por 24 horas, quando então serão determinados os pesos da matéria seca, em balança analítica.

Os dados obtidos de peso de massa seca total da planta (raiz + caule + folha) e $\mathrm{a}$ área foliar total, foram utilizados para os cálculos da taxa de crescimento absoluto (TCA), taxa assimilatória líquida (TAL) e taxa de crescimento relativo (TCR), através das fórmulas de Hunt (1978), o conteúdo relativo de água foi determinado segundo o método de Slavick (1979).

O conteúdo relativo de água (Figura 1) foi superior nas folhas das plantas controle quando comparado ao tratamento submetido ao alagamento, esse fato mostra que a redução do conteúdo relativo de água foi causada pelo fechamento dos estômatos, provocado por alterações 
metabólicas geradas em virtudes da anoxia das raízes. Esse resultado se difere do encontrado por Freitas et al. (2007) em açaizeros sob alagamento, pois afirmam que as plantas sob alagamentos apresentaram alto teor relativo de água nas células, pois o solo esta sempre acima da capacidade de campo.

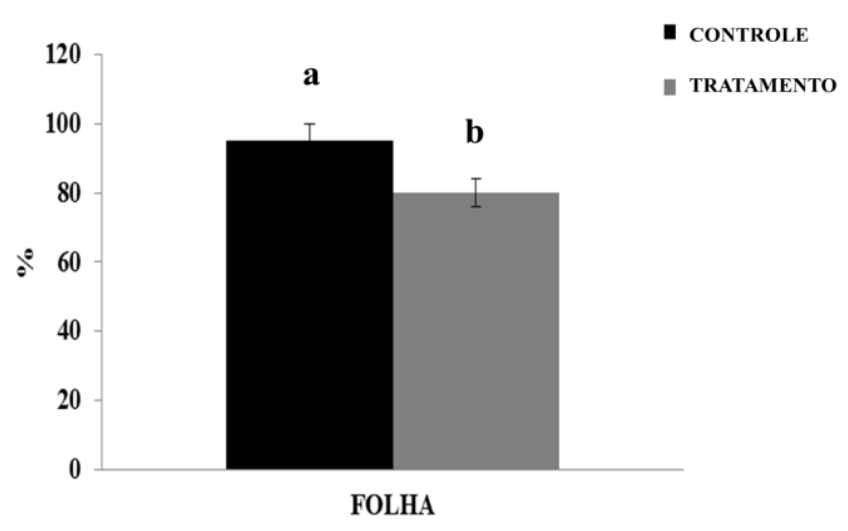

Figura 1. Conteúdo relativo de água nas folhas de plantas de milho submetidas durante 10 dias sob alagamento. As letras diferentes mostram diferença estatística, comparadas pelo teste Tukey ao nível de $5 \%$ de probabilidade.

A transpiração (Figura 2) foi afetada significativamente nas plantas submetidas ao estresse por alagamento. Em geral, em plantas sob efeito do alagamento, ocorre à diminuição da absorção de água, tanto pela redução do comprimento e superfície total das raízes, como conseqüência da sua morte, como pelo aumento da resistência ao fluxo de água. Pesquisa realizada por Ajaz e Mzk (2009) com milho alagado mostraram que vai haver uma queda na taxa de transpiração foliar.
Para a condutância estomática (Figura 3) também se obteve resultados que mostraram que as plantas foram afetadas pelo estresse por alagamento. Em muitas plantas sob alagamento do solo, uma das primeiras respostas ecofisiológicas observadas é o fechamento estomático (CHEN et al., 2002), considerado um compotamento regulador do balanço hídrico durante episódios de alagamento. Como foi observado em trabalhos realizados por Arruda e Calbo (2004) em tomateiro. 


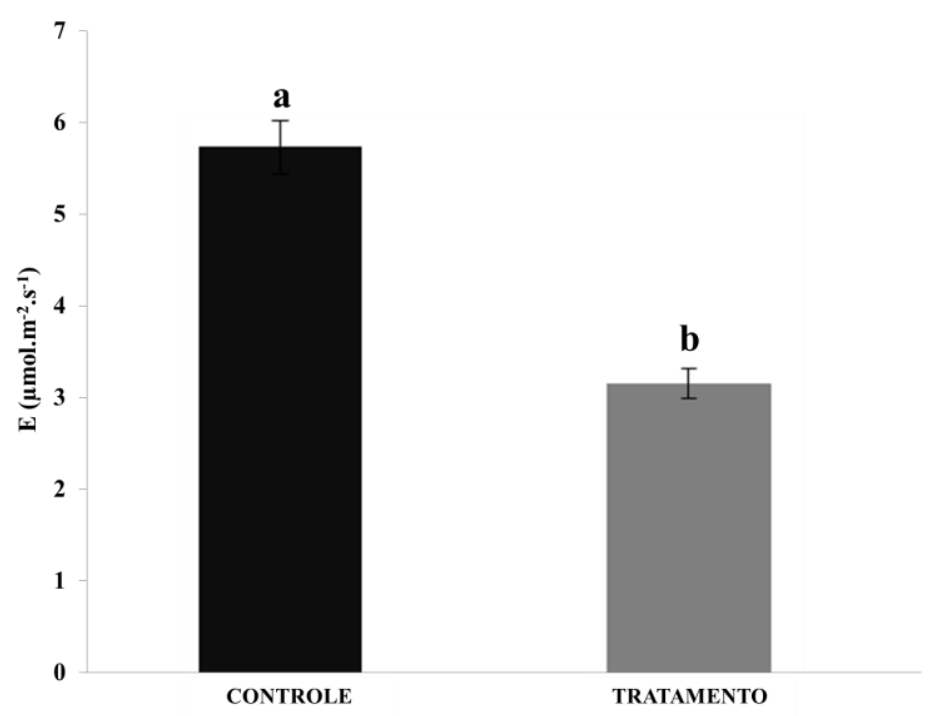

Figura 2. Transpiração em plantas de milho submetidas durante 10 dias sob alagamento.

Foi observada uma maior razão na relação raiz/parte aérea em massa seca para as plantas em alagamento, evidenciando uma maior alocação de recursos nas raízes.

Deve se ao fato, que quando os nutrientes são reduzidos, as espécies têm uma menor taxa de crescimento e aumentam a alocação de biomassa para as raízes, sendo este um mecanismo de adquirir recursos através de ajustes de plasticidade morfológica. Resultados semelhantes foram encontrados por Vieira e Gomes (2011) quando trabalharam com plantas de pau-terra-do-cerrado em alagamento.

Os valores de massa seca total nas plantas controle foram maiores do que nas plantas sob alagamento (Figura 4b), verificando que plantas sob o estresse de alagamento têm o seu desenvolvimento afetado pelos processos fisiológicos, podendo ser consequência da redução da concentração de oxigênio no sistema radicular. Resultados semelhantes foram verificados por Zenzen et al. (2006) em plantas de soja sob regime de alagamento.

As plantas, sob alagamento, tiveram baixo conteúdo relativo de água, diminuição da transpiração foliar, consequência da redução da condutância estomática, as plantas tiveram seu crescimento afetado, devido ás alterações bioquímicas sofridas pelo alagamento e consequentemente perda de produtividade quando comparadas as plantas não alagadas. 


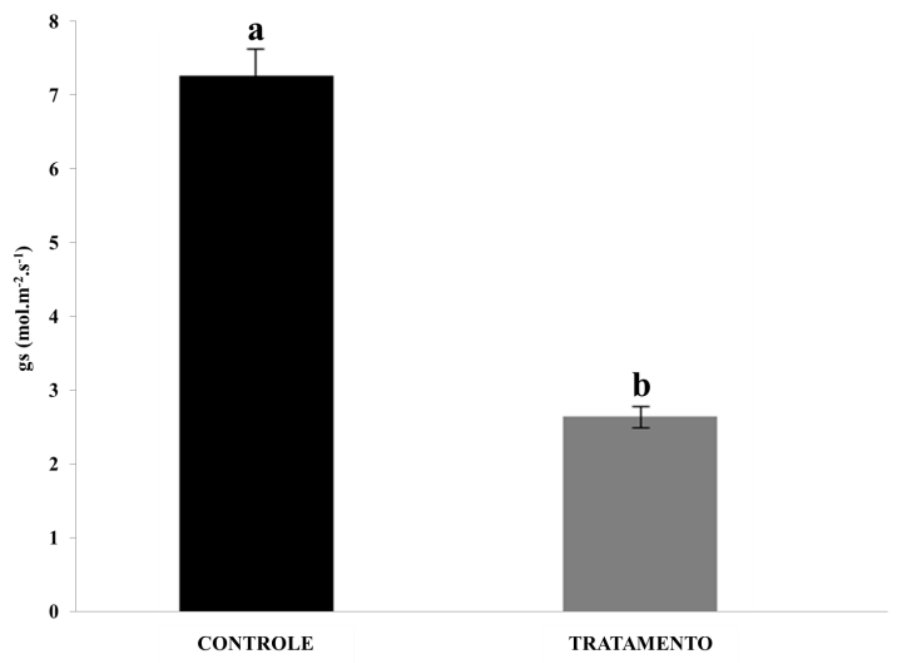

Figura 3. Condutância estomática em plantas de milho submetidas durante 10 dias sob alagamento.
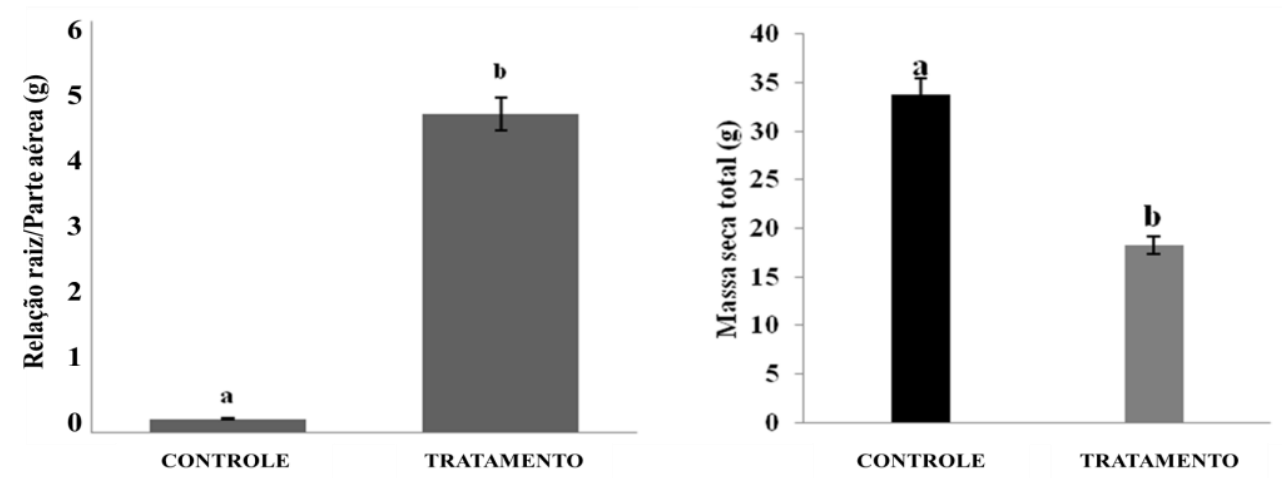

Figura 4. Relação raiz/parte aérea (A) massa seca total (B) em plantas de milho submetidas durante 10 dias sob alagamento.

\section{REFERÊNCIAS}

AJAZ, A. L.; MZK, W. Response of Maize

( Zea mays L.) To Excess Soil Moisture (ESM) Tolerance at Different Stages of Life Cycle. Botany Research International v. 2, n. 3, p. 211-217, 2009. ARRUDA, G. M. T.; CALBO, M. E. R. Efeitos da inundação no crescimento, trocas gasosas e porosidade radicular da carnaúba (Copernicia prunifera (Mill.) H.E. Moore). Acta Bot. Bras., São Paulo, v. 18, n. $2,2004$.

CHEN, H.; QUALLS, R. G.; MILLER, G. C. Adaptative responses of Lepidiumlatifoliumto soil flooding: biomass allocation, adventitious rooting, aerenchyma formation and ethylene production. Environmental and 
Experimental Botany, v. 48, n. 2, p.119128, 2002.

FREITAS, J. M. N.; CARVALHO, K. S.; LOBATO, A. K. S.; CASTRO, D. S.; MAIA, P. S. P.; OLIVEIRA NETO, C. F.; COSTA, R. C. L. Atividade da Redutase do Nitrato, Conteúdo relativo de Água e teores de Clorofilas Solúveis totais em Folhas de Açaizeiro (Euterpe edulis Mart.) submetidas ao Déficit Hídrico e ao Alagamento. Revista Brasileira de Biociências, Porto Alegre, v. 5, supl. 2, p. 924-926, 2007.

GOMES, F. P; GARCIA, C. H. Estatística aplicada a experimentos agronômicos e florestais exposição com exemplos e orientações para uso de aplicativos. Piracicaba: FEALQ, 2002. 309 p.

SLAVICK, B. Methods of studyng plant water relations. Springer Verlang, p. 449, 1979

SUMMARY for Policymakers. In: SOLOMON, S.; QIN, D.; MANNING, M.; CHEN, Z.; MARQUIS, M.; AVERYT, K. B.; TIGNOR, M.; MILLER, H. L. Climate Change: The Physical Science Basis. Cambridge: Cambridge University Press, , 2007. p. 1-18.

VIEIRA, E. A.; GOMES, A. S. Desenvolvimento inicial em plantas jovens de pau-terra-do-cerrado sob diferentes regimes hídricos. Evolução e Conservação da Biodiversidade. 2011. Disponível em: <www.simposiodabiodiversidade.com.br/e cb.2011>. Acesso em: 10 de maio de 2013.

ZENZEN, I. L.; FONSECA, C. S.; OLIVEIRA, M.; BERNARDI, E; AMARANTE, L.; COLARES, D. Influência do alagamento no acúmulo de matéria seca em plantas de soja inoculadas com diferentes estirpes de bradyrhizobium. In: CONGRESSO DE INICIAÇÃO CIENTIFICA, 15., 2006. 